\title{
In search of risk factors for chronic pain in adolescents: a case-control study of childhood and parental associations
}

\author{
Alies Coenders' \\ Cindy Chapman ${ }^{2}$ \\ Patricia Hannaford ${ }^{3}$ \\ Tiina Jaaniste ${ }^{2,3}$ \\ Wen Qiu \\ David Anderson ${ }^{2}$ \\ Maline Glogauer ${ }^{2}$ \\ Evelyn Goodison- \\ Farnsworth ${ }^{2}$ \\ Marianne McCormick ${ }^{2}$ \\ David Champion ${ }^{2,3}$ \\ 'University of Groningen, Groningen, \\ The Netherlands; ' ${ }^{2}$ Department of \\ Anaesthesia and Pain Medicine, \\ Sydney Children's Hospital, \\ Randwick, NSW, Australia; ${ }^{3}$ University \\ of New South Wales, Kensington, \\ NSW, Australia
}

This article was published in the following Dove Press journal:

Journal of Pain Research

27 March 2014

Number of times this article has been viewed

Objectives: This study was designed to investigate whether an individual and parental history of functional pain syndromes (FPS) is found more often in adolescents suffering from chronic pain than in their pain-free peers.

Methods: Our case-control study involved 101 adolescents aged 10-18 years. Cases were 45 patients of the Chronic Pain Clinic at Sydney Children's Hospital with diverse chronic pain disorders. Controls consisted of 56 adolescent volunteers who did not have chronic pain. Adolescents and their parents filled out questionnaires assessing demographic data as well as known and potential risk factors for chronic pain. A history of FPS was assessed by questionnaire, including restless legs syndrome (RLS). Chi-squared tests and $t$-tests were used to investigate univariate associations between chronic pain in adolescents and lifetime prevalence of FPS. Logistic regression was used to test multivariate associations, while controlling for possible confounders.

Results: Migraine, non-migraine headaches, recurrent abdominal pain (RAP), and RLS were reported significantly more frequently in cases than controls ( $P$-values of $0.01,<0.001,0.01$, and 0.03 , respectively). Parental migraine, RAP, and RLS were also significantly associated with adolescent chronic pain in the multivariate analyses. Individual history of migraine, nonmigraine headaches, and RAP, along with parental history of RAP and depression significantly accounted for $36 \%-49 \%$ of variance in chronic pain. Other associations with chronic pain were generally in accordance with previous reports.

Discussion: It may be helpful when assessing a child who has chronic pain or is at risk of chronic pain, to enquire about these associations. Based on the current findings, an individual history of migraine, non-migraine headaches, and RAP, as well as parental migraine, RAP, and RLS are symptoms that are of particular relevance to assess.

Keywords: chronic adolescent pain, functional pain syndromes, restless legs syndrome, adolescents, parental history

\section{Introduction}

Chronic and recurrent pain disorders affect a considerable proportion of the adolescent population, with prevalence rates ranging $6 \%-54 \% .{ }^{1-7}$ Unexplained chronic pain (ie, without significant injury or disease) is commonly referred to as non-specific, idiopathic, ${ }^{8}$ or functional pain. ${ }^{9}$ The most prevalent functional pain syndromes (FPS) in early childhood are growing pains (GP), non-migraine headaches, and recurrent abdominal pain (RAP), while children and adolescents are also at risk of migraine, neck and back pains, chronic widespread pain, and its subset fibromyalgia. These disorders are often comorbid simultaneously or sequentially, with multiple pain disorders increasing the intensity of pain experiences. ${ }^{6,10-13}$ Furthermore, there are remarkable
Correspondence: David Champion Department of Anesthesia and Pain Medicine, Sydney Children's Hospital, High Street, Randwick,

NSW 203I, Australia

Tel +6I 293821585

Email dchamp@bigpond.net.au 
associations between restless legs syndrome (RLS) and the common functional pain disorders of childhood and adolescence. ${ }^{14}$ FPS impair daily activities and often have a negative impact on everyday functioning, resulting in a lower quality of life. ${ }^{15,16}$

There is some evidence to suggest that a history of FPS in childhood is predictive of pain disorders later in life. ${ }^{17-21}$ However, there has been a lack of publications assessing early childhood FPS or parental history of FPS, as potential risk factors for chronic pain in adolescents. In addition to an individual and parental history of FPS, previous studies have investigated known and potential risk factors for the development of pain disorders in adolescence, including (early) childhood factors and psychological factors. ${ }^{3,6,13,22-33}$

The primary objective of the current study was to investigate, using a case-control study design, possible associations between chronic adolescent pain and preceding FPS and RLS, and such conditions in their parents. It was hypothesized that an individual or parental history of FPS and RLS would be found more often in adolescents suffering from chronic pain than in their pain-free peers. A secondary objective was to investigate the effect of other early childhood factors and other parental factors on adolescent FPS and to identify and control for potential confounders.

\section{Materials and methods}

This research was carried out as a cross-sectional case-control study. Informed consent was obtained from adolescents and their parents. The protocol was approved by the Human Research Ethics Committee of the South Eastern Sydney and Illawarra Area Health Service. Questionnaire distribution occurred from September 2009 to February 2011.

\section{Participants}

Participants were aged between 10 and 18 years. Eligible cases were consenting adolescents who were currently or recently suffering from chronic pain, with chronic pain being defined as having had regional or widespread pain for longer than 3 months. ${ }^{34}$ Cases were recruited from past or current attendees of the Chronic Pain Clinic at Sydney Children's Hospital, Australia. Patients and their parents were approached in the waiting room, by mail, or by telephone, and were asked to fill out questionnaires at home. These were completed either online or on hard-copy.

The control group consisted of adolescents who did not have a current chronic pain condition and who were participating in a community service program at the hospital. Additional controls were recruited by visiting secondary schools in the proximity of the hospital. Thirty minutes of the community service hospital program, or, alternatively, the science class, were allocated to filling in the questionnaires under supervision of the researcher. Hard-copies were taken home to be completed by the parents and to be returned to the hospital in a pre-paid envelope.

\section{Measures and assessments}

The adolescent questionnaire assessed socio-demographic factors, pain characteristics, childhood factors, and psychological factors. The parent questionnaire assessed early childhood factors, pain syndromes, and psychological factors in their child, as well as pain syndromes and psychological factors in each of the parents (Questionnaires are available from authors on request).

\section{Pain characteristics in cases: location, intensity, disability}

To assess the occurrence of chronic pain, thereby distinguishing between cases and controls, adolescents were asked whether they had experienced pain that lasted longer than three months during adolescence. If yes, they were requested to report the diagnosis, the age of onset, and the location of their pain using a body chart. ${ }^{35,36}$

The 'Faces Pain Scale" ${ }^{37}$ was used to assess current pain intensity. This scale consists of gender-neutral drawings of faces, each with facial expressions differentiating various levels of pain. The FPS has been validated as a measure of pain intensity in children. ${ }^{37,38}$ Participants in the current study were asked to circle the face that best represented the worst intensity of pain they had experienced in the past week.

The 'Functional Disability Inventory (FDI) ${ }^{39}$ was used as a measure of the impact of the pain on daily functioning. The FDI is a measure of illness-related limitations in activity and social functioning. It has been validated for use in children and adolescents and has been found to have good concurrent and predictive validity as well as strong internal consistency reliability. ${ }^{39,40}$ Respondents are required to indicate whether over the past few days they have had any physical trouble or difficulty in doing each of 15 everyday activities. Disability is rated on a scale from 0 ('no trouble') to 5 ('impossible'). A total FDI score is obtained by adding the scores for all 15 items. A total FDI score ranging from 13 to 29 has been considered to reflect moderate disability, while a score of more than 30 reflects severe disability. ${ }^{41}$

\section{FPS in adolescents and parents}

A FPS parent-report checklist was developed for the purposes of the current study to assess adolescent and 
parent lifetime history of FPS. The parent completing the checklist was asked to indicate whether the adolescent, or either of their parents, had ever experienced any of the FPS conditions (migraine, non-migraine headaches, RAP, fibromyalgia) or RLS. RLS in adolescents was further identified by a screening question ${ }^{42}$ ("When you try to relax in the evening or sleep at night, do you ever have unpleasant, restless feelings in your legs that can be relieved by walking or movement?"). Further, parents were asked to complete a measure of GP for themselves and their child, based on the widely accepted diagnostic criteria established by Peterson in $1986 .{ }^{43}$

\section{Childhood factors in adolescents}

A survey of childhood factors was developed for the purposes of the current study and administered to adolescents and parents to assess for early childhood and current factors that are possible or known risk factors for subsequent pain. Adolescents were asked to report the time in hours currently spent on physical exercise, sedentary activity (eg, watching TV or playing on the computer), and playing a musical instrument. Information was also obtained concerning adverse life events (eg, death of a family member and parental divorce) and medical history (eg, medication use, hospitalization, and serious injuries). The parent questionnaire addressed further early childhood factors regarding their child, including prematurity, birth weight, serious injuries, hospitalization, adverse life events, prolonged fatigue, acute pain problems, living away from home, low iron, low vitamin $\mathrm{D}$, and academic level.

\section{Psychological functioning in adolescents and their parents}

The 'Depression Anxiety Stress Scale (DASS-21)' ${ }^{94}$ was administered to the adolescents and their parents to assess psychological functioning. The DASS-21 is a 21 -item measure designed to assess symptoms of depression, anxiety, and general stress over the past 1 -week period. Items are scored on a scale from 0 ('Did not apply to me at all') to 3 ('Applied to me very much of the time'). The DASS-21 has been found to have good internal consistency and a stable factor structure..$^{45}$ The measure has been validated for use in adolescents ${ }^{45,46}$ and adults. ${ }^{47,48}$

\section{Data analysis}

Differences between cases and controls were assessed using Yates' chi-squared tests and Fisher's exact tests for categorical variables and independent $t$-tests for continuous variables.
Where parents' and adolescents' answers contained inconsistencies, analysis was conducted using data obtained from the parents' questionnaire only, as these answers were considered generally more valid.

In analysing the association between chronic pain and the occurrence of preceding FPS, the primary chronic pain diagnoses reported by cases were not included in the analysis. Furthermore, when the primary chronic pain diagnosis was an extension of an earlier FPS, such as migraine and nonmigraine headaches, that particular FPS was not included in the analysis. Thus only FPS unrelated to the primary chronic pain diagnosis were used to analyze differences in frequency of FPS reported by cases and controls, thereby minimizing bias.

Logistic regression was conducted to develop a model of multivariate associations as potential predictors of chronic pain in adolescents. Other relevant variables that were previously univariately found to be statistically associated to chronic pain were tested as possible confounders.

\section{Results Descriptives}

Completed questionnaires were received from 45 cases, with a response rate of $54 \%$. Of the controls, 56 returned the questionnaire. Participation rates were not calculated for controls, as there was no precise record of the number of adolescents approached at the secondary schools.

The gender distribution in both groups was similar, showing a female predominance. Among the cases were 30 females $(66.7 \%)$ and 15 males (33.3\%), compared to 35 females $(62.5 \%)$ and 21 males $(37.5 \%)$ in the control group. On average, cases were slightly younger than controls, with a mean age of 14.1 years (SD 2.2, range 10-18) and 15.5 years (SD 1.3, range 13-17), respectively $(t[69]=3.81$, 95\% confidence interval $[\mathrm{CI}]: 0.67-2.20, P<0.001)$.

\section{Pain characteristics in cases: location, intensity, disability}

Of the primary chronic pain diagnoses that were reported by the cases, RAP was the most common, being reported by nine cases $(20 \%)$. Migraine and non-migraine headaches were reported by five cases $(11.1 \%)$ and GP by one case $(2.2 \%)$. A total of 27 cases $(60 \%)$ reported a syndrome other than GP, migraine, non-migraine headaches, RAP, and RLS. In this category, the most common were chronic widespread pain/fibromyalgia, chronic regional pain/limb pain, and neuropathic pain. For three cases $(6.7 \%)$, the primary chronic pain diagnosis was unknown at the time of 
questionnaire completion. On the 'Faces Pain Scale', cases reported a mean maximum pain intensity in the previous week of 4.0 (SD 1.9, range 1-7). On the FDI, cases scored a mean of 13 (SD 11.9, range 0-46), which was considered moderate disability.

\section{Univariate analyses}

\section{FPS in adolescents and parents}

As shown in Table 1, cases reported more lifetime FPS than controls. Given the negatively skewed distribution for number of FPS, a logarithmic transformation was carried out (after a discrete value of 1 was added to remove zero responses) before a $t$-test was computed to assess for differences between cases and controls. The average lifetime number of FPS reported by cases (excluding their primary chronic pain diagnosis) was significantly higher than in controls: cases reported an average of $1.31 \mathrm{FPS}$, relative to 0.30 in controls $(t[77]=4.82$, CI: $0.34-0.71, P<0.001)$. Adolescents who reported a total lifetime history of at least 3 FPS (including RLS) were significantly more likely to have chronic pain in adolescence (odds ratio [OR] $=10.1, \mathrm{CI}: 1.20-85.7$ [Fisher's exact test], $P=0.02$ ).

When comparing cases to controls, a difference was found in the specific type of FPS that they reported (Table 2). After excluding the primary chronic pain diagnosis and any FPS that were directly related to this primary diagnosis, the most common additional FPS in the case group was non-migraine headaches (28.9\%), closely followed by RAP (24.4\%). Controls most commonly reported GP (7.1\%). Case adolescents reported an individual past history of migraines, non-migraine headaches, RAP, and RLS significantly more often than the controls (Table 2).

The parents of adolescents with chronic pain were significantly more likely to report having migraines, RAP, or RLS currently or in the past (Table 3). Significant relationships were not found between adolescent chronic pain and parental GP, non-migraine headaches, fibromyalgia, or other pain syndromes.

Table I Individual history of prior FPS: total number of FPS reported by cases and controls

\begin{tabular}{llll}
\hline & \multicolumn{1}{c}{ Cases $(\mathbf{N}=\mathbf{4 5})$} & & Controls ( N = 56) \\
\cline { 2 - 2 } & $\mathbf{N}(\%)$ & & $\mathbf{N}(\%)$ \\
\hline Reporting no FPS & $13(28.9)$ & $45(80.4)$ \\
Reporting I FPS & $17(37.8)$ & $6(10.7)$ \\
Reporting 2 FPS & $5(11.1)$ & $4(7.1)$ \\
Reporting 3 FPS & $8(17.8)$ & $\mathrm{I}(\mathrm{I} .8)$ \\
Reporting 4 FPS & $2(4.4)$ & $0(0)$ \\
\hline
\end{tabular}

Abbreviation: FPS, functional pain syndromes.
Table 2 Individual history of prior FPS: specific FPS reported by cases and controls

\begin{tabular}{|c|c|c|c|c|c|}
\hline & $\begin{array}{l}\text { Cases } \\
(\mathbf{N}=45) \\
\mathbf{N}(\%)\end{array}$ & $\begin{array}{l}\text { Controls } \\
(N=56) \\
N(\%)\end{array}$ & $P$-value & OR & $95 \% \mathrm{Cl}$ \\
\hline GP & $8(17.8)$ & $4(7.1)$ & 0.18 & 2.8 & $0.8-10.0$ \\
\hline Migraine & $10(22.2)$ & $2(3.6)$ & 0.01 & 7.7 & I.6-37.3 \\
\hline $\begin{array}{l}\text { Non-migraine } \\
\text { headaches }\end{array}$ & I 3 (28.9) & I (I.8) & $<0.001$ & 22.3 & $2.8-178.9$ \\
\hline RAP & II (24.4) & $3(5.4)$ & 0.01 & 5.7 & I.5-22.0 \\
\hline RLS & $10(22.2)$ & $3(5.4)$ & 0.03 & 5.1 & $1.3-19.7$ \\
\hline Other & 7 (I4.9) & $4(7.1)$ & 0.34 & 2.28 & $0.6-8.3$ \\
\hline
\end{tabular}

Abbreviations: $\mathrm{Cl}$, confidence interval; $\mathrm{FPS}$, functional pain syndromes; GP, growing pains; OR, odds ratio; RAP, recurrent abdominal pain; RLS, restless legs syndrome.

\section{Childhood factors in adolescents}

Chi-square and Fisher's exact tests revealed a number of (mostly early) childhood factors to be significantly associated with chronic pain in adolescents (Table 4). Chronic pain in adolescence was significantly associated with a lower academic level, history of serious injury, history of adversity, use of medication, the experience of prolonged fatigue, iron deficiency, and being low in vitamin D. Sedentary activity, as assessed by watching television, was of borderline significance. For adolescents with a history of serious injury, the most common were fractures (cases: $62.5 \%$; controls: $66.7 \%$ ). Adversity was mostly specified as experiencing the death of a family member (61.8\%), parental divorce (17.6\%), and serious illness of a family member (11.8\%).

\section{Psychological functioning in adolescents and parents}

A lifetime history of depression or anxiety requiring intervention in adolescents was reported by parents significantly more often in cases than controls ( $\mathrm{OR}=7.7, P=0.01$ and $\mathrm{OR}=3.4, P=0.04$, respectively). However, adolescent cases and controls did not differ significantly in terms of

Table 3 Parental history of functional pain syndromes

\begin{tabular}{|c|c|c|c|c|c|}
\hline & $\begin{array}{l}\text { Cases } \\
\left(\begin{array}{l}N=45) \\
\end{array}(\%)\right.\end{array}$ & $\begin{array}{l}\text { Controls } \\
(\mathbf{N}=56) \\
\mathbf{N}(\%)\end{array}$ & $P$-value & OR & $95 \% \mathrm{Cl}$ \\
\hline GP & $7(15.6)$ & $5(8.9)$ & 0.48 & 1.9 & $0.6-6.4$ \\
\hline Migraine & $23(5 I . I)$ & I5 (27.3) & 0.03 & 2.8 & $1.2-6.4$ \\
\hline $\begin{array}{l}\text { Non-migraine } \\
\text { headaches }\end{array}$ & $9(20.0)$ & $10(18.2)$ & 1.00 & I.I & $0.4-3.1$ \\
\hline RAP & $18(40.0)$ & $6(10.9)$ & 0.00 & 5.4 & $1.9-15.4$ \\
\hline RLS & $12(26.7)$ & $4(7.3)$ & 0.02 & 4.6 & $1.4-15.6$ \\
\hline Fibromyalgia & I (2.2) & $2(3.6)$ & $1.00^{\dagger}$ & 0.6 & $0.1-6.9$ \\
\hline Other & $7(15.6)$ & $7(12.7)$ & 0.91 & 1.3 & $0.4-3.9$ \\
\hline
\end{tabular}

Note: 'Fisher's exact test.

Abbreviations: $\mathrm{Cl}$, confidence interval; GP, growing pains; OR, odds ratio; RAP, recurrent abdominal pain; RLS, restless legs syndrome. 
Table 4 Associations in (early) childhood with chronic pain in adolescents

\begin{tabular}{|c|c|c|c|c|c|}
\hline & \multirow{2}{*}{$\frac{\text { Cases }(\mathrm{N}=45)}{\mathrm{N}(\%)}$} & \multirow{2}{*}{$\frac{\text { Controls }(\mathrm{N}=56)}{\mathrm{N}(\%)}$} & \multirow[t]{2}{*}{$P$-value } & \multirow[t]{2}{*}{ OR } & \multirow[t]{2}{*}{$95 \% \mathrm{Cl}$} \\
\hline & & & & & \\
\hline Academic level (below average) & $15(33.3)$ & $8(14.3)$ & 0.04 & 3.0 & $1.1-7.9$ \\
\hline Birth weight (low $[<2.5$ grams]) & $4(9.1)$ & $3(6.4)$ & $0.7 \mathrm{I}^{\dagger}$ & 1.5 & $0.3-7.0$ \\
\hline Prematurity & $6(13.3)$ & $4(7.1)$ & $0.33^{\dagger}$ & 2.0 & $0.5-7.6$ \\
\hline Hospitalization & $23(52.3)$ & $22(39.3)$ & 0.27 & 1.7 & $0.8-3.8$ \\
\hline Serious injury & $10(22.2)$ & $3(5.4)$ & 0.03 & 5.1 & $1.3-19.7$ \\
\hline Adversity & $21(46.7)$ & $13(23.2)$ & 0.02 & 2.9 & $1.2-6.8$ \\
\hline Acute pain & $24(53.3)$ & $26(46.4)$ & 0.62 & 1.3 & $0.6-2.9$ \\
\hline Living away from home & $5(I I . I)$ & $5(8.9)$ & $0.75^{\dagger}$ & 1.3 & $0.4-4.7$ \\
\hline Use of medication & $28(66.7)$ & $5(9.8)$ & $<0.001$ & 18.4 & $6.0-56.6$ \\
\hline Using the computer ( $>2.5$ hours a day) & $13(31.0)$ & II (2I.2) & 0.40 & 1.7 & $0.7-4.3$ \\
\hline Watching TV ( $>2.5$ hours a week) & $9(21.4)$ & $3(5.8)$ & 0.05 & 4.5 & I.I-17.7 \\
\hline Playing instrument ( $>5$ hours a week) & $2(4.8)$ & $7(13.5)$ & $0.18^{\dagger}$ & 0.3 & $0.1-1.6$ \\
\hline Prolonged fatigue & $20(44.4)$ & $6(10.7)$ & $<0.001$ & 6.7 & $2.4-18.7$ \\
\hline Low iron & II (24.4) & $4(7.3)$ & 0.04 & 4.1 & $1.2-14.0$ \\
\hline Low vitamin D & $6(13.3)$ & $\mathrm{I}(1.8)$ & $0.04^{\dagger}$ & 8.3 & $1.0-71.8$ \\
\hline Hypermobility & $3(7.1)$ & $4(7.7)$ & $1.00^{\dagger}$ & 0.9 & $0.2-4.4$ \\
\hline Physical exercise ( $>2.5$ hours a week) & $26(61.9)$ & $38(73.1)$ & 0.35 & 0.6 & $0.3-1.4$ \\
\hline
\end{tabular}

Note: 'Fisher's exact test.

Abbreviations: $\mathrm{Cl}$, confidence interval; $\mathrm{OR}$, odds ratio.

current depression $(\mathrm{OR}=3.1, P=0.09)$ and current anxiety $(\mathrm{OR}=1.5, P=0.51)$ scores on the DASS-21. Similarly, while self-reported history of depression and stress in parents showed a significant correlation with chronic pain in adolescents $(\mathrm{OR}=4.5, P<0.001$ and $\mathrm{OR}=2.8, P=0.03$, respectively), current DASS-21 ratings for the same variables failed to show any such association $(\mathrm{OR}=1.3, P=0.75$ and $\mathrm{OR}=0.9, P=1.00$, respectively).

\section{Multivariate analysis}

A model, including an individual history of previous RAP, migraine and non-migraine headaches, was designed to predict chronic pain in the adolescents while controlling for confounders. GP and RLS were excluded from the model, due to an insufficient and multicollinear correlation with chronic adolescent pain, respectively. The only independent variables that significantly influenced the relationship between chronic adolescent pain and an individual history of prior FPS were parental history of RAP and self-reported parental depression; all other variables previously found to be univariately associated with chronic adolescent pain were excluded from the model. Given the sample size of $\mathrm{N}=101$, this model, with five independent variables, had sufficient power (power $=0.80, \alpha=0.05$ ) to detect medium effect sizes (if these exist). The model was shown to sufficiently predict chronic pain outcomes in adolescents, as proven by Omnibus tests $<0.05$ and the Hosmer and Lemeshow test $>0.05$ (Omnibus tests of model: $P<0.001$; Hosmer and
Lemeshow test: $P=0.10$ ). It had a relatively high predictive ability and explained $36.4 \%-48.7 \%$ of the variance of chronic pain in adolescents. Furthermore, the model could correctly classify $77.8 \%$ of all cases and controls, as opposed to $54.5 \%$ of the study population being correctly classified when the independent variables were not included in the model. The contribution of each of the independent variables is displayed in Table 5.

\section{Discussion}

This study sought to investigate an individual and parental history of functional pain syndromes (FPS) as possible risk factors or associations with subsequent chronic pain in adolescents. Although 'functional' has at times been used for an essentially psychogenic condition ignoring the evidence of neurobiological dysfunction, we have chosen to use this

Table 5 Variables in the multivariate model for statistical prediction of chronic pain in adolescents

\begin{tabular}{llll}
\hline & P-value & OR & $\mathbf{9 5 \%} \mathbf{C l}$ \\
\hline $\begin{array}{l}\text { Individual history of } \\
\quad \text { Migraine }\end{array}$ & 0.03 & 7.8 & $1.3-48.4$ \\
$\quad$ Non-migraine headaches & 0.01 & 18.3 & $2.0-170.0$ \\
$\quad$ RAP & 0.01 & 8.2 & $1.7-40.0$ \\
$\begin{array}{l}\text { Parental history of } \\
\quad \text { RAP }\end{array}$ & 0.02 & 5.1 & $1.4-18.8$ \\
$\quad$ Depression & 0.02 & 4.4 & $1.3-14.9$ \\
\hline
\end{tabular}

Abbreviations: $\mathrm{Cl}$, confidence interval; $\mathrm{OR}$, odds ratio; $\mathrm{RAP}$, recurrent abdominal pain. 
terminology, taking the lead from Mayer and Bushnell. ${ }^{9}$ These authors challenge the specific end-organ concept and emphasise the shared epidemiological, clinical, and biological features of the disorders reviewed. Furthermore, they put forward evidence of common genetic susceptibility. The disorders we have chosen to include in this study fall within the functional pain group which they identified. Also, we have evidence of the associations with each other and indications of common vulnerability. ${ }^{10,49}$

\section{FPS in adolescents and parents}

Our results indicate a significant association between chronic pain in adolescents and an individual history of prior FPS, particularly regarding migraine, non-migraine headaches, RAP, and also RLS. This is the first study to test multiple FPS as potential predictive factors for chronic pain in adolescents. In a recent study, Walker and colleagues found that $35 \%$ of their population that suffered from childhood RAP continued to have chronic pain in adulthood. ${ }^{17}$ Similarly, previous studies reported that early RAP and chronic widespread pain increase the likelihood of chronic pain symptoms on 1-year and 4-year follow-up. ${ }^{18-20}$ These findings that link certain FPS with chronic pain later in life are in agreement with our results.

Associations between chronic adolescent pain and an individual history of GP were not statistically significant. The odds ratio of 2.8 found regarding GP in individual history raises the question as to whether a larger research sample might be needed to establish such associations.

Regarding a parental history of FPS, associations with chronic pain in adolescents were found for parental migraine, RAP, and RLS. Our results support the view that recurrent or functional pain syndromes might be genetically influenced and share heritable vulnerability traits, as supported by recent studies. ${ }^{10,50-52}$ No significant associations were found with respect to parental GP, non-migraine headaches, and other FPS. These results were surprising when compared to previous research on this topic, and may be due to our relatively small sample size. ${ }^{53-56}$

\section{Multivariate analysis}

A noteworthy strength of this present study is that logistic regression was used to verify whether the associations found with regards to the primary objective were independent or whether they were biased by confounding factors. A model was proposed to verify whether the associations concerning the primary objective were correct or whether confounding factors were of influence. The model showed that an individual history of migraine, non-migraine headaches, and RAP, along with parental RAP and parental depression were the major factors associated with chronic adolescent pain and might represent independent predictors. These findings are in line with our expectations and with the literature, as previously discussed.

\section{Childhood factors in adolescents}

In addition to an individual and parental history of FPS, previous studies have addressed further known and potential risk factors for the development of pain disorders in adolescence. These conditions were included in the protocol to be controlled for as potential confounders. These include age, ${ }^{19,21}$ gender, ${ }^{3,5,6,13,15,19,21}$ low birth weigh, ${ }^{22}$ prematurity, ${ }^{24}$ childhood stress such as living away from home, adversity, serious injury, acute pain, hospitalization, ${ }^{21,23,25,57,58}$ use of excess health services and medication, ${ }^{26,27}$ sedentary activity, ${ }^{30}$ excessive exercise, ${ }^{20,28,30,59}$ hypermobility, ${ }^{28,60}$ prolonged fatigue, ${ }^{29,59,61,62}$ low vitamin $\mathrm{D},{ }^{31,63,64}$ and iron deficiency. ${ }^{32,65,66}$

In this study, the female predominance in the case group was typical and reflects the results of previous research. Two comparable studies illustrated that girls report higher frequencies of recurrent pain and comorbidity of pain syndromes than boys, particularly after menarche. ${ }^{3,13}$ The gender distribution was no different in the controls, where a similar female predominance was determined. The lack of difference in the numbers of female cases and controls was an advantage in the current study as it ensured a more homogenous study population.

Associations were found between chronic pain in the adolescents and the variables age and academic level; both were lower in cases than controls. However, these relationships were unexpected and not in agreement with the literature. ${ }^{19,21}$ The results may be attributed to the recruitment of the controls, who were approached during extracurricular activities that might be attended more frequently by students in higher grades and talented/gifted classes. Furthermore, the assessments of academic status were current and it is possible that respondents with chronic pain were underperforming compared to their potential.

The associations found between childhood factors and chronic pain in adolescents, such as serious injury, adversity, prolonged fatigue, iron deficiency, and low vitamin $\mathrm{D}$, were in accordance with the literature..$^{23,25,29,31,32,57,59,61-66}$ Medication use in the cases was largely current and consequent to the chronic pain. In contrast to the literature, this study did not find a significant association between chronic pain 
in adolescents and low birth weight, prematurity, and hospitalization, ${ }^{22-25,57,58}$ and was not powered to do so.

\section{Psychological functioning in adolescents and parents}

Previous research has identified psychological disorders in adolescents, ${ }^{33,67-73}$ as well as in their families, ${ }^{74,75}$ to be associated with chronic adolescent pain. Similarly, the current study found that individual anxiety and depression, as well as parental depression and stress, were significantly associated with chronic pain in adolescents. These associations were found when assessed through a global adolescent/ parent self-assessment of anxiety, depression, and stress, but surprisingly not when assessed through a questionnaire of psychological functioning.

Given that this study assessed current, rather than preceding, psychological factors, it is not possible to draw conclusions about the etiology or direction of the association. However, there is evidence from the literature to suggest that psychological factors are significant risk factors for pain syndromes, ${ }^{33}$ in addition to being the consequence of chronic pain.

\section{Limitations}

This study has several limitations that should be considered when interpreting the results. First, the relatively small sample size might have reduced our ability to detect other potentially statistically significant differences between the cases and controls. While this study was sufficiently powered to show important associations, it was underpowered to detect multiple less frequent associations with chronic adolescent pain, such as some childhood factors. However, we were not addressing known associations as a primary aim of the study, but assessed these factors to allow controlling for the most important confounders.

Second, data were obtained using questionnaires and were primarily based on self-report. Steps were undertaken to minimize biased recall, such as having parents confirm (early) childhood factors and favouring parents' answers when adolescent and parent questionnaires contained inconsistencies. Despite these precautions, the data may have been subject to social desirability and other reporting biases, as well as inadequate recall.

Third, the study sample was not completely representative with regards to the sociodemographic population. Cases and controls differed in age and seemed to come primarily from middle and upper socioeconomic classes. The slightly older age of the controls, however, will have allowed more time for life prevalence of FPS and thus any age confounding would have tended to reduce the significance of associations between chronic pain and prior FPS.

Finally, although the case-control design enables identifying several associations simultaneously in a relatively small population, this design also has its limitations. ${ }^{76}$ The method of selection of suitable controls is always an issue, and limitations occur because the research has to be within the bounds of practicable recruitment. Case-control studies cannot determine causal direction of associations. Rather, the associations found are hypothesis generating, guiding testing by higher order methods.

\section{Implications and directions for future research}

As the current study is the first to test FPS as potential predictors for subsequent chronic pain in adolescents, it lays the foundation for further examination of risk factors for chronic pain in adolescents. Research on this subject might result in a better understanding of FPS and their etiology, possibly leading to improved prevention, earlier intervention, and better treatment.

Future research should aim to achieve a larger sample size and more unbiased methods of data collection. It should include designs to determine the trajectory and inter-relationships between childhood FPS, by obtaining the exact age of onset of these disorders. Furthermore, FPS should be tested as independent risk factors for chronic pain in both adolescents and adults. Prospective cohort studies and randomized controlled trials are appropriate designs to achieve these goals, having found support for a reasonable hypothesis that FPS are risk factors for chronic pain disorders in adolescents and probably adults. ${ }^{76}$

\section{Acknowledgments}

We acknowledge with appreciation the leadership of Dr Matthew Crawford, Head of the Department of Anaesthesiology and Pain Medicine at Sydney Children's Hospital, for his vision in inspiring this collaborative work effort, the assistance of Play Therapist Michelle Perrin in the early stages of the research, the input of Associate Professor George Chalkiadis, at the Royal Children's Hospital Melbourne, and the statistical guidance of Professor Jennifer Peat. Thanks also to Monica Cook, for assisting in the recruitment of adolescent controls, as well as the school teachers for facilitating the testing.

\section{Disclosure}

The authors report no conflicts of interest in this work. 


\section{References}

1. van Dijk A, McGrath PA, Pickett W, VanDenKerkhof EG. Pain prevalence in nine- to 13-year-old schoolchildren. Pain Res Manag. 2006;11(4):234-240.

2. Dunn KM, Jordan KP, Mancl L, Drangsholt MT, Le Resche L. Trajectories of pain in adolescents: a prospective cohort study. Pain. 2011;152(1):66-73.

3. Stanford EA, Chambers CT, Biesanz JC, Chen E. The frequency, trajectories and predictors of adolescent recurrent pain: a populationbased approach. Pain. 2008;138(1):11-21.

4. Huguet A, Miro J. The severity of chronic pediatric pain: an epidemiological study. J Pain. 2008;9(3):226-236.

5. Perquin CW, Hazebroek-Kampschreur AA, Hunfeld JA, et al. Pain in children and adolescents: a common experience. Pain. 2000;87(1): 51-58.

6. Kroner-Herwig B, Gassmann J, van Gessel H, Vath N. Multiple pains in children and adolescents: a risk factor analysis in a longitudinal study. J Pediatr Psychol. 2011;36(4):420-432.

7. King S, Chambers CT, Huguet A, et al. The epidemiology of chronic pain in children and adolescents revisited: a systematic review. Pain. 2011;152(12):2729-2738.

8. Diatchenko L, Nackley AG, Slade GD, Fillingim RB, Maixner W. Idiopathic pain disorders - pathways of vulnerability. Pain. 2006; 123(3):226-230

9. Mayer EA, Bushnell MC, editors. Functional Pain Syndromes: Presentation and Pathophysiology. Seattle: IASP Press; 1999.

10. von Baeyer CL, Champion GD. Commentary: multiple pains as functional pain syndromes. J Pediatr Psychol. 2011;36(4):433-437.

11. Kato K, Sullivan PF, Evengard B, Pedersen NL. A population-based twin study of functional somatic syndromes. Psychol Med. 2009;39(3):497-505.

12. Kanaan RA, Lepine JP, Wessely SC. The association or otherwise of the functional somatic syndromes. Psychosom Med. 2007;69(9): 855-859.

13. Larsson B, Sund AM. Emotional/behavioural, social correlates and oneyear predictors of frequent pains among early adolescents: influences of pain characteristics. Eur J Pain. 2007;11(1):57-65.

14. Chapman C, Kofman R, Champion D, et al. Paediatric Restless Legs Syndrome is associated with multiple functional pain syndromes in childhood: a twin family case control study. In: Abstracts of the Australian Pain Society Annual Scientific meeting; March 17-20, 2013; Canberra, Australia.

15. Hunfeld JA, Perquin CW, Duivenvoorden HJ, et al. Chronic pain and its impact on quality of life in adolescents and their families. J Pediatr Psychol. 2001;26(3):145-153.

16. Roth-Isigkeit A, Thyen U, Stoven H, Schwarzenberger J, Schmucker P. Pain among children and adolescents: restrictions in daily living and triggering factors. Pediatrics. 2005;115(2):e152-e162.

17. Walker LS, Dengler-Crish CM, Rippel S, Bruehl S. Functional abdominal pain in childhood and adolescence increases risk for chronic pain in adulthood. Pain. 2010;150(3):568-572.

18. Dengler-Crish CM, Horst SN, Walker LS. Somatic complaints in childhood functional abdominal pain are associated with functional gastrointestinal disorders in adolescence and adulthood. $J$ Pediatr Gastroenterol Nutr. 2011;52(2):162-165.

19. El-Metwally A, Salminen JJ, Auvinen A, Kautiainen H, Mikkelsson M. Prognosis of non-specific musculoskeletal pain in preadolescents: a prospective 4-year follow-up study till adolescence. Pain. 2004; 110(3):550-559.

20. Jones GT, Silman AJ, Macfarlane GJ. Predicting the onset of widespread body pain among children. Arthritis Rheum. 2003;48(9):2615-2621.

21. Mikkelsson M, El-Metwally A, Kautiainen H, Auvinen A, Macfarlane GJ, Salminen JJ. Onset, prognosis and risk factors for widespread pain in schoolchildren: a prospective 4-year follow-up study. Pain. 2008;138(3):681-687.

22. Mallen CD, Peat G, Thomas E, Croft PR. Is chronic musculoskeletal pain in adulthood related to factors at birth? A population-based casecontrol study of young adults. Eur J Epidemiol. 2006;21(3):237-243.
23. Mallen CD, Peat G, Thomas E, Croft PR. Is chronic pain in adulthood related to childhood factors? A population-based case-control study of young adults. J Rheumatol. 2006;33(11):2286-2290.

24. Grunau RV, Whitfield MF, Petrie JH, Fryer EL. Early pain experience, child and family factors, as precursors of somatization: a prospective study of extremely premature and fullterm children. Pain. 1994;56(3): 353-359.

25. Jones GT, Power C, Macfarlane GJ. Adverse events in childhood and chronic widespread pain in adult life: results from the 1958 british birth cohort study. Pain. 2009;143(1-2):92-96.

26. Miro J, Huguet A, Nieto R. Predictive factors of chronic pediatric pain and disability: a delphi poll. J Pain. 2007;8(10):774-792.

27. Campo JV, Comer DM, Jansen-Mcwilliams L, Gardner W, Kelleher KJ. Recurrent pain, emotional distress, and health service use in childhood. J Pediatr. 2002;141(1):76-83.

28. El-Metwally A, Salminen JJ, Auvinen A, Kautiainen H, Mikkelsson M. Lower limb pain in a preadolescent population: prognosis and risk factors for chronicity - a prospective 1- and 4-year follow-up study. Pediatrics. 2005;116(3):673-681.

29. Mikkelsson M, Salminen JJ, Sourander A, Kautiainen H. Contributing factors to the persistence of musculoskeletal pain in preadolescents: a prospective 1-year follow-up study. Pain. 1998;77(1):67-72.

30. Heneweer H, Vanhees L, Picavet HS. Physical activity and low back pain: a U-shaped relation? Pain. 2009;143(1-2):21-25.

31. Knutsen KV, Brekke M, Gjelstad S, Lagerlov P. Vitamin D status in patients with musculoskeletal pain, fatigue and headache: a crosssectional descriptive study in a multi-ethnic general practice in norway. Scand J Prim Health Care. 2010;28(3):166-171.

32. Picchietti MA, Picchietti DL. Advances in pediatric restless legs syndrome: iron, genetics, diagnosis and treatment. Sleep Med. 2010;11(7):643-651.

33. Janssens KA, Rosmalen JG, Ormel J, van Oort FV, Oldehinkel AJ. Anxiety and depression are risk factors rather than consequences of functional somatic symptoms in a general population of adolescents: the TRAILS study. J Child Psychol Psychiatry. 2010;51(3):304-312.

34. McGrath PA. Chronic pain in children. In: Crombie IK, Croft PR, Linton SJ, Leresche L, Von Korff M, editors. Epidemiology of Pain. Seattle: IASP Press; 1999:81-100.

35. Savedra MC, Tesler MD, Holzemer WL, Wilkie DJ, Ward JA. Pain location: validity and reliability of body outline markings by hospitalized children and adolescents. Res Nurs Health. 1989;12(5): 307-314.

36. von Baeyer CL, Lin V, Seidman LC, Tsao JC, Zeltzer LK. Pain charts (body maps or manikins) in assessment of the location of pediatric pain. Pain Manag. 2011;1(1):61-68.

37. Bieri D, Reeve RA, Champion GD, Addicoat L, Ziegler JB. The faces pain scale for the self-assessment of the severity of pain experienced by children: development, initial validation, and preliminary investigation for ratio scale properties. Pain. 1990;41(2):139-150.

38. McGrath PJ, Walco GA, Turk DC, et al. Core outcome domains and measures for pediatric acute and chronic/recurrent pain clinical trials: PedIMMPACT recommendations. J Pain. 2008;9(9):771-783.

39. Walker LS, Greene JW. The functional disability inventory: measuring a neglected dimension of child health status. J Pediatr Psychol. 1991;16(1):39-58.

40. Claar RL, Walker LS. Functional assessment of pediatric pain patients: psychometric properties of the functional disability inventory. Pain. 2006;121(1-2):77-84.

41. Kashikar-Zuck S, Flowers SR, Claar RL, et al. Clinical utility and validity of the functional disability inventory among a multicenter sample of youth with chronic pain. Pain. 2011;152(7):1600-1607.

42. Ferri R, Lanuzza B, Cosentino FI, et al. A single question for the rapid screening of restless legs syndrome in the neurological clinical practice. Eur J Neurol. 2007;14(9):1016-1021.

43. Peterson H. Growing pains. Pediatr Clin North Am. 1986;33(6): 1365-1372. 
44. Lovibond SH, Lovibond LP. Manual for the Depression Anxiety Stress Scales. 2nd ed. Sydney: Psychology Foundation; 1995.

45. Tully PJ, Zajac IT, Venning AJ. The structure of anxiety and depression in a normative sample of younger and older Australian adolescents. J Abnorm Child Psychol. 2009;37(5):717-726.

46. Szabo M. The short version of the depression anxiety stress scales (DASS-21): factor structure in a young adolescent sample. J Adolesc. 2010;33(1):1-8.

47. Henry JD, Crawford JR. The short-form version of the depression anxiety stress scales (DASS-21): construct validity and normative data in a large non-clinical sample. Br J Clin Psychol. 2005;44(Pt 2): 227-239.

48. Brown TA, Chorpita BF, Korotitsch W, Barlow DH. Psychometric properties of the depression anxiety stress scales (DASS) in clinical samples. Behav Res Ther. 1997;35(1):79-89.

49. Champion D. Genetic influences and associations of common idiopathic/ functional pain syndromes of childhood: evidence from twin family case-control studies. In: Abstracts of the Annual Scientific Meeting of the Faculty of Pain Medicine Australian and New Zealand College of Anaesthetists; May 4-8, 2013; Melbourne, Australia.

50. Gieteling MJ, Bierma-Zeinstra SM, van Leeuwen Y, Passchier J, Berger MY. Prognostic factors for persistence of chronic abdominal pain in children. J Pediatr Gastroenterol Nutr. 2011;52(2):154-161.

51. Muhle H, Neumann A, Lohmann-Hedrich K, et al. Childhood-onset restless legs syndrome: clinical and genetic features of 22 families. Mov Disord. 2008;23(8):1113-1121; quiz 1203.

52. Russell MB, Hilden J, Sorensen SA, Olesen J. Familial occurrence of migraine without aura and migraine with aura. Neurology. 1993;43(7): 1369-1373.

53. Arnold LM, Hudson JI, Hess EV, et al. Family study of fibromyalgia. Arthritis Rheum. 2004;50(3):944-952.

54. Buskila D, Neumann L, Hazanov I, Carmi R. Familial aggregation in the fibromyalgia syndrome. Semin Arthritis Rheum. 1996;26(3): 605-611.

55. Evans AM. Growing pains: Contemporary knowledge and recommended practice. $J$ Foot Ankle Res. 2008;1(1):4

56. Arruda MA, Guidetti V, Galli F, Albuquerque RC, Bigal ME. Frequency of headaches in children is influenced by headache status in the mother. Headache. 2010;50(6):973-980.

57. Boey CC, Goh KL. The significance of life-events as contributing factors in childhood recurrent abdominal pain in an urban community in Malaysia. $J$ Psychosom Res. 2001;51(4):559-562.

58. McBeth J, Morris S, Benjamin S, Silman AJ, Macfarlane GJ. Associations between adverse events in childhood and chronic widespread pain in adulthood: are they explained by differential recall? $J$ Rheumatol. 2001;28(10):2305-2309.

59. El-Metwally A, Salminen JJ, Auvinen A, Macfarlane G, Mikkelsson M. Risk factors for development of non-specific musculoskeletal pain in preteens and early adolescents: a prospective 1-year follow-up study. BMC Musculoskelet Disord. 2007;8:46.

60. Gedalia A, Press J, Klein M, Buskila D. Joint hypermobility and fibromyalgia in schoolchildren. Ann Rheum Dis. 1993;52(7): 494-496.
61. El-Metwally A, Halder S, Thompson D, Macfarlane GJ, Jones GT. Predictors of abdominal pain in schoolchildren: a 4-year population-based prospective study. Arch Dis Child. 2007;92(12):1094-1098.

62. Hamilton WT, Gallagher AM, Thomas JM, White PD. Risk markers for both chronic fatigue and irritable bowel syndromes: a prospective casecontrol study in primary care. Psychol Med. 2009;39(11):1913-1921.

63. Prakash S, Bhanvadia RJ, Shah ND. Restless legs syndrome with carbamazepine-induced osteomalacia: causal or casual association. Gen Hosp Psychiatry. 2010;32(2):228. e1-e3.

64. Prakash S, Mehta NC, Dabhi AS, Lakhani O, Khilari M, Shah ND. The prevalence of headache may be related with the latitude: a possible role of vitamin D insufficiency? J Headache Pain. 2010;11(4):301-307.

65. Quinn C, Uzbeck M, Saleem I, et al. Iron status and chronic kidney disease predict restless legs syndrome in an older hospital population. Sleep Med. 2011;12(3):295-301.

66. Pamuk GE, Pamuk ON, Set T, Harmandar O, Yesil N. An increased prevalence of fibromyalgia in iron deficiency anemia and thalassemia minor and associated factors. Clin Rheumatol. 2008;27(9): $1103-1138$.

67. Tsao JC, Allen LB, Evans S, Lu Q, Myers CD, Zeltzer LK. Anxiety sensitivity and catastrophizing: associations with pain and somatization in non-clinical children. $J$ Health Psychol. 2009;14(8):1085-1094.

68. Goldenberg DL. Pain/depression dyad: a key to a better understanding and treatment of functional somatic syndromes. Am J Med. 2010; 123(8):675-682.

69. Means-Christensen AJ, Roy-Byrne PP, Sherbourne CD, Craske MG, Stein MB. Relationships among pain, anxiety, and depression in primary care. Depress Anxiety. 2008;25(7):593-600.

70. Asmundson GJ, Katz J. Understanding the co-occurrence of anxiety disorders and chronic pain: state-of-the-art. Depress Anxiety. 2009;26(10):888-901.

71. Ligthart L, Nyholt DR, Penninx BW, Boomsma DI. The shared genetics of migraine and anxious depression. Headache. 2010;50(10): 1549-1560.

72. Feldman JM, Ortega AN, Koinis-Mitchell D, Kuo AA, Canino G. Child and family psychiatric and psychological factors associated with child physical health problems: results from the Boricua youth study. J Nerv Ment Dis. 2010;198(4):272-279.

73. van der Veek SM, Derkx HH, de Haan E, Benninga MA, Boer F. Abdominal pain in Dutch schoolchildren: relations with physical and psychological comorbid complaints in children and their parents. J Pediatr Gastroenterol Nutr. 2010;51(4):481-487.

74. Ramchandani PG, Stein A, Hotopf M, Wiles NJ. Early parental and child predictors of recurrent abdominal pain at school age: results of a large population-based study. J Am Acad Child Adolesc Psychiatry. 2006;45(6):729-736.

75. Kashikar-Zuck S, Lynch AM, Slater S, Graham TB, Swain NF, Noll RB. Family factors, emotional functioning, and functional impairment in juvenile fibromyalgia syndrome. Arthritis Rheum. 2008;59(10): 1392-1398.

76. Rosmalen JG. The way forward: a case for longitudinal population-based studies in the field of functional somatic syndromes. J Psychosom Res. 2010;68(5):399-401.
Journal of Pain Research

\section{Publish your work in this journal}

The Journal of Pain Research is an international, peer-reviewed, open access, online journal that welcomes laboratory and clinical findings in the fields of pain research and the prevention and management of pain. Original research, reviews, symposium reports, hypothesis formation and commentaries are all considered for publication.

\section{Dovepress}

The manuscript management system is completely online and includes a very quick and fair peer-review system, which is all easy to use. Visit http://www.dovepress.com/testimonials.php to read real quotes from published authors. 